\title{
New approaches to designing parts for digital additive production ${ }^{\mathrm{a}}$
}

\author{
Evgeny Borisov ${ }^{1}$, Alexei Orlov ${ }^{1 *}$, and Nikolai Razumov ${ }^{1}$ \\ ${ }^{1}$ Center of National Technological Initiative "New Production Technologies" of Peter the Great \\ St.Petersburg Polytechnic University. 195251, Polytechnicheskaya st., 29, Russian Federation
}

\begin{abstract}
In accordance with a concept of additive technologies there occurs a necessity of applying new approaches to designing parts. One of the main tools to be operated is a numerical simulation, capable of providing a designer with the complex approach to the development of new articles in case of finesse. A preliminary simulation model of structurally-gradient materials in the software package ANSYS has been created in this work for predicting mechanical characteristics of compact samples of materials and structures. It provides the results of tensile calculations of stress strain behavior of samples obtained by finite-element simulation, as well as gives comparison thereof with the test data obtained after manufacturing using a method of selective laser melting.
\end{abstract}

\section{Introduction}

Digital data surround people already during long period of time permanently growing both quantitatively and qualitatively. Digital production is an integrated computer system including devices of numerical simulation, 3D visualization, engineering analysis and joint work intended for the development of structures of articles and production processes of manufacturing thereof. Digital production is a product of the fourth industrial revolution, the so-called "Industry 4.0". Digital production makes it possible to effect simulation modeling of production processes, receive a feedback from real process operations build it into a process article designing. One of the lines of production most suitable for changeover to a new industry level is the additive production.

The additive production is the process of manufacturing parts in the way of adding materials layer by layer. This technology makes it possible to produce finished articles with very intricate configuration, which is difficult or absolutely impossible to manufacture using traditional methods [1]. The additive technologies include such technologies as selective laser sintering (SLS), direct metal deposition (DED), electron-beam melting (EBM), selective laser melting (SLM). One of the most intensively developing technologies of additive production is the selective laser melting of metal powder materials, which is being widely incorporated into technological chains [1].

\footnotetext{
a The research was carried out in the context of implementing Federal Target Program "Research and development works on priority development fields of science and technology sector of Russia for 20142020", unique project identifier RFMEFI57817X0245

*Corresponding author: orlov alexey88@mail.ru
} 
In order to build digital infrastructure in the framework of additive technologies, it is necessary to solve many additional problems, for instance, such as predicting mechanical characteristics of compact samples of materials and structures of structurally-gradient materials [2]. In order to solve the set problem, it is necessary to work out a preliminary calculation model. The development of preliminary calculation model will be effected in the software package ANSYS. This software package makes it possible to build various calculation models with the use of a wide set of calculation modules, perform static, dynamic, hydrodynamic and other types of calculations [3]. It will be necessary to carry out simulation of sample expansion process in the framework of this work, hence, it will be necessary to use the calculation mechanics module. The samples will be manufactured using selective laser melting method with the use of metal powder Inconel 718 as the source material. In order to create the structurally-gradient samples, it is necessary to use different capabilities while manufacturing thereof.

\section{Materials and investigation methods}

The compact samples have been fabricated at the installation of selective laser melting SLM280HL of SLM Solutions GmbH. The powder of heat-resistant nickel alloy Inconel 718 produced by means of gas atomization has been used as the source material. The measured chemical composition of powder of alloy Inconel 718 is shown in Table 1.

Table 1. Chemical composition of particles of powder Inconel 718 (measured by means of energy dispersive spectroscopy)

\begin{tabular}{|l|l|l|l|l|l|l|l|l|l|}
\hline Element & $\mathrm{Ni}$ & $\mathrm{Cr}$ & $\mathrm{Fe}$ & $\mathrm{Nb}$ & $\mathrm{Mo}$ & $\mathrm{Ti}$ & $\mathrm{Al}$ & $\mathrm{Co}$ & $\mathrm{Mn}$ \\
\hline Content, \% wt. & 51.4 & 19.4 & 18.5 & 5.3 & 3.4 & 1.0 & 0.7 & 0.1 & 0.1 \\
\hline
\end{tabular}

The tests for determining mechanical properties have been carried out in accordance with ISO 6892-1 at test machine Zwick/Roell Z100 (Germany) with maximum force of 99,640 N.

The development of preliminary calculation model has been performed in the software package ANSYS Workbench. This software package makes it possible to create different calculation models with the use of a wide set of calculation modules, perform static, dynamic, hydrodynamic and other types of calculations. The simulation of sample expansion process has been carried out in the framework of this work, hence, for which purpose the calculation mechanics module has been used [4]. First of all, the calculation models of homogeneous samples have been developed, the results have been compared with experimental data [5]. After that, the obtained results have been used for calculating strength characteristics of samples with variable structure.

\section{Work results and discussion thereof}

\subsection{Investigation of mechanical characteristics of samples}

Mechanical characteristics of heat-resistant nickel alloy Inconel 718 obtained after selective laser melting have been used in this work [6]. As it has been shown before, shaping of different structure [6] and, as a result, mechanical characteristics take place depending on the used technological parameters of the process of selective laser melting.

The investigations have been performed using homogeneous samples and samples with variable structure, which dimensions are shown in Fig. 1, a and 1, b, accordingly. 
a)
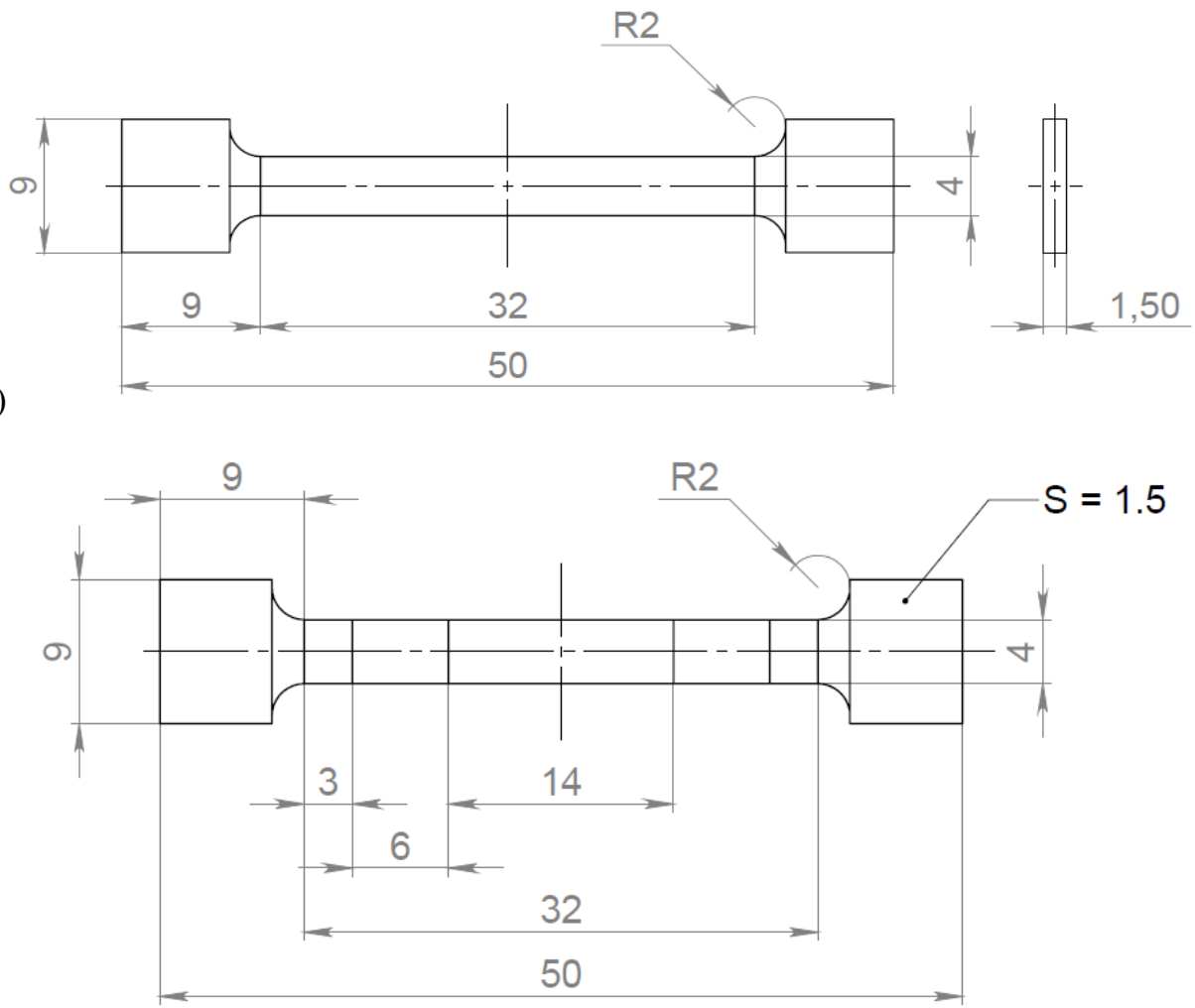

b)

Fig. 1. Dimensions of homogeneous samples (a) and samples with variable structure (b).

The central inserts as wide as $6 \mathrm{~mm}$ in a sample with a variable structure have been fabricated with using layer thickness of $100 \mu \mathrm{m}$, when the rest part of the sample has a thickness of $50 \mu \mathrm{m}$.

The mechanical properties of homogeneous samples fabricated with the use of different technological parameters of the process of selective laser melting are shown in Table 2, and the samples with variable structure - in Table 3.

Table 2. Mechanical characteristics of samples made of Inconel 718 with two modes of lasers operation.

\begin{tabular}{|c|c|c|c|}
\hline $\begin{array}{c}\text { Layer } \\
\text { thickness, } \boldsymbol{\mu m}\end{array}$ & $\begin{array}{c}\text { Proportional limit } \\
\text { load, } \mathbf{M P a}\end{array}$ & $\begin{array}{c}\text { Young modulus, } \\
\mathbf{M P a}\end{array}$ & $\begin{array}{c}\text { Ultimate tensile strength, } \\
\mathbf{M P a}\end{array}$ \\
\hline 50 & $645.1 \pm 6.2$ & $188.3 \pm 8.1$ & $1,024.9 \pm 14.1$ \\
\hline 100 & $481.2 \pm 11.9$ & $184.9 \pm 51.7$ & $788.2 \pm 12.2$ \\
\hline
\end{tabular}

Table 3. Mechanical characteristics of samples made of Inconel 718 with variable structure.

\begin{tabular}{|c|c|c|}
\hline $\begin{array}{c}\text { Proportional limit } \\
\text { load, MPa }\end{array}$ & $\begin{array}{c}\text { Young modulus, } \\
\text { MPa }\end{array}$ & $\begin{array}{c}\text { Ultimate tensile strength, } \\
\text { MPa }\end{array}$ \\
\hline $500.2 \pm 6.4$ & $187.1 \pm 8.6$ & $816.9 \pm 15.8$ \\
\hline
\end{tabular}




\subsection{Building calculation model for analyzing mechanical characteristics and comparing calculation results with experimental data}

According to data of results of investigating mechanical properties there are data for Young modulus. We select the first variant: Young modulus and Poisson factor. The value of Poisson factor is taken from Table and equals 0.29, Young modulus equals $1.9734 \mathrm{e} 5 \mathrm{MPa}$. Modulus of volume elasticity and shear modulus get automatically calculated according to the known formulae (1):

$$
\begin{aligned}
& K=\frac{E}{3(1-2 v)} \\
& G=\frac{E}{2(1+v)}
\end{aligned}
$$

where, $K$ - modulus of volume elasticity, $E$ - Young modulus, v - Poisson factor, $G$ - shear modulus.

Basic analysis settings are shown below:

- Number of Steps - 19;

- Auto Time Stepping - Off;

- Defined by -Substeps;

- Time Integration -On;

- Solver Type - Direct;

- Large Deflection-On.

According to the data of investigating mechanical properties of material time of finishing the last calculation stage equal to $520 \mathrm{~s}$ has been set, rate of grip transfer amounted to 1.5 $\mathrm{mm} / \mathrm{s}$. 
Fig. 2 presents samples at the moment of shaping a neck of plastic strains with stress distribution as per sample 3D model.

a)
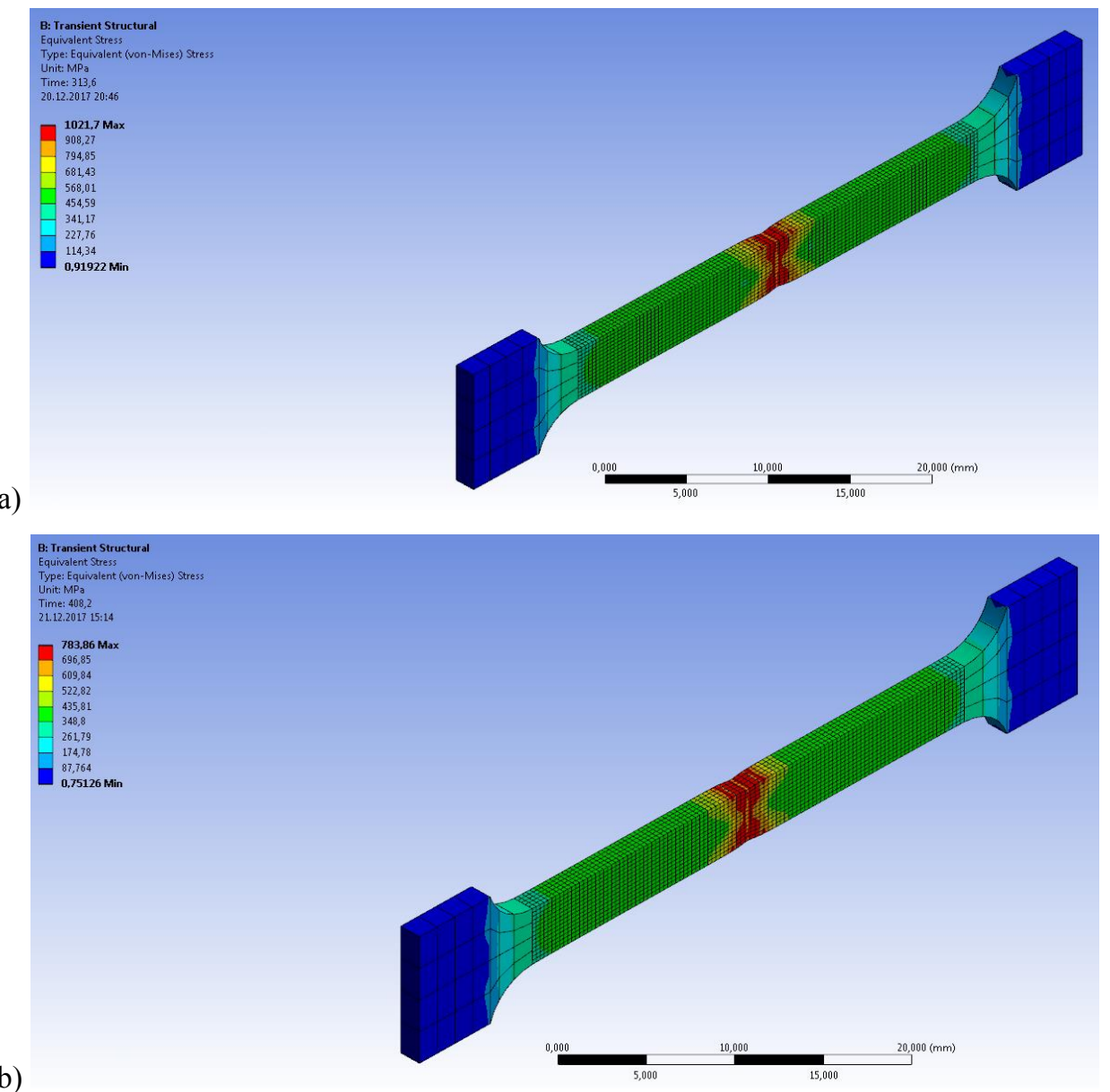

Fig. 2. Model of sample with displayed distribution of stresses. a - for Layer thickness of $50 \mu \mathrm{m}, \mathrm{b}-$ for layer thickness of $100 \mu \mathrm{m}$. 


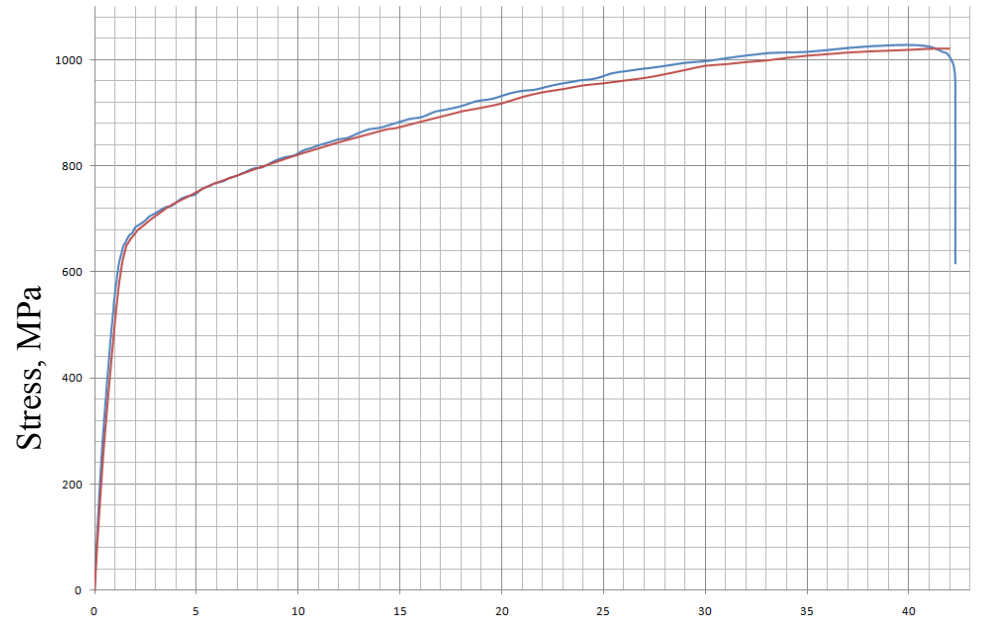

a) Strain, $\mathrm{mm} \mathrm{mm}^{-1}$

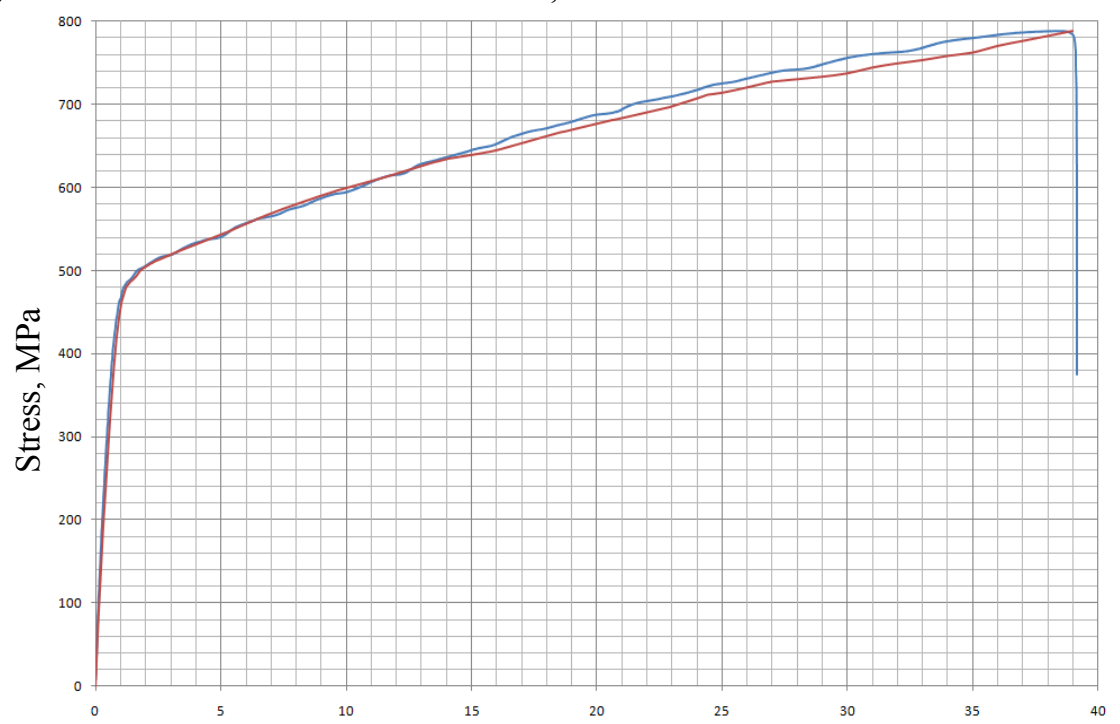

b)

Strain, $\mathrm{mm} \mathrm{mm}^{-1}$

Fig. 3. Comparing graphs of dependencies of stresses vs. strains: data of investigating sample for mechanical properties are shown in blue; data of computer simulation results are shown in red. a - for layer thickness of $50 \mu \mathrm{m}, \mathrm{b}-$ for layer thickness of $100 \mu \mathrm{m}$. 
Fig. 4 presents 3D model of structural-gradient sample with mesh and allocated properties of materials.

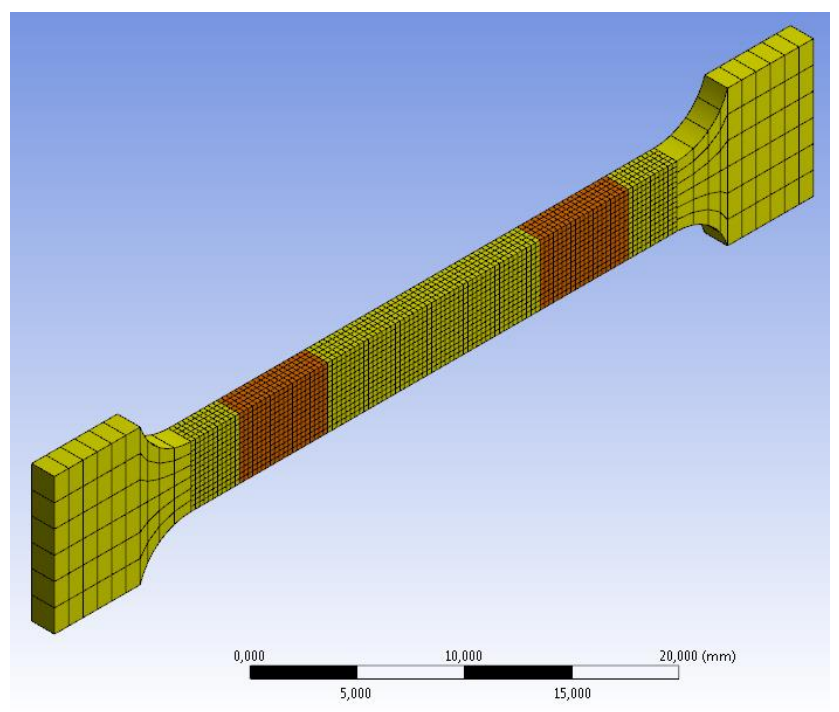

Fig. 4. Model of Structural-Gradient Sample with Mesh. Datum Made with Layer Thickness of 50 $\mu \mathrm{m}-$ Yellow Color; Inserts Made with Layer Thickness of $100 \mu \mathrm{m}$ - Orange Color.

The computer simulation of process of sample extension resulted in obtaining a set of data, which have been compared with data of investigating samples for mechanical properties during stretching. Fig. 5 shows a sample with a variable structure at the moment of shaping a neck of plastic strains with stress distribution, Fig. 6 shows a comparison of calculated and experimental curve of stress dependence vs. strain during tensile test.

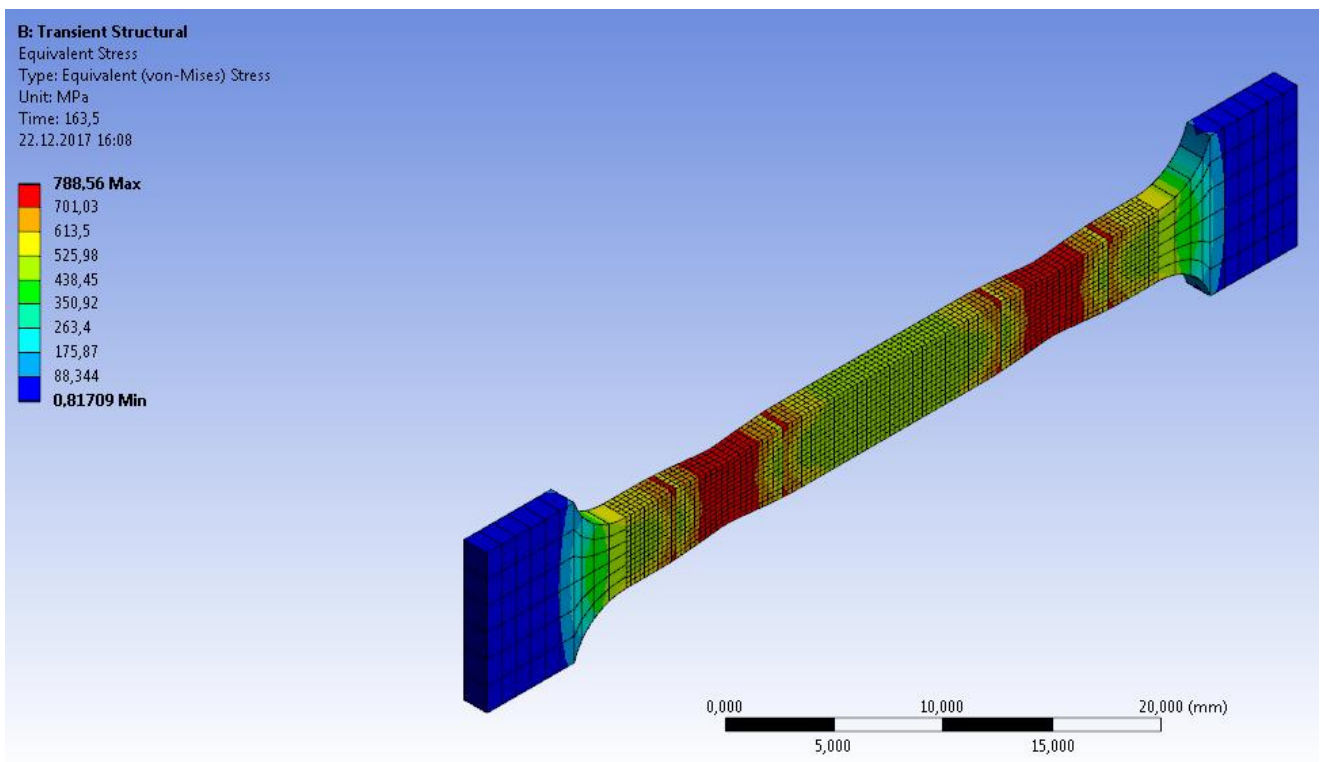

Fig. 5. Model of sample with variable structure with displayed distribution of stresses. 


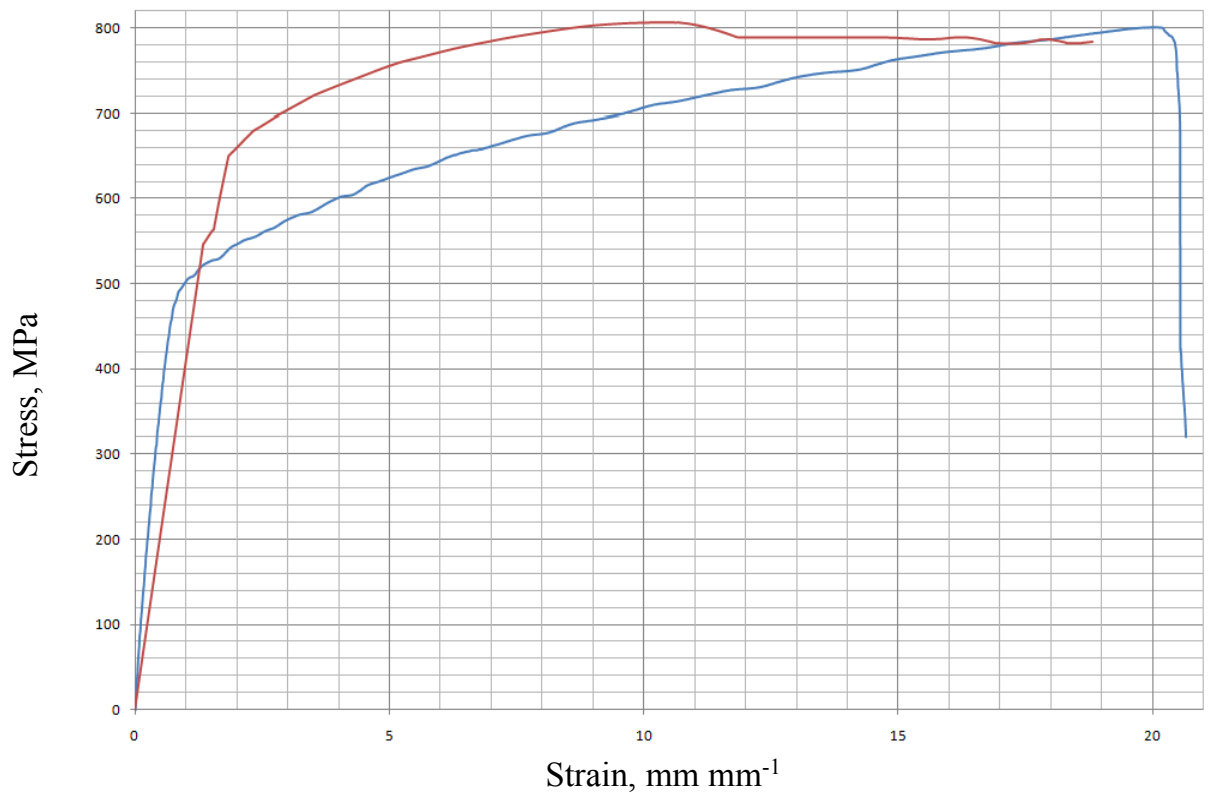

Fig. 6. Comparison of graphs of dependences of stresses vs. strains: data of investigating sample for mechanical properties are shown in blue; data of computer simulation results are shown in red.

\section{Conclusions}

The comparison of data has shown a discrepancy between experimental and calculated data. It is also shown in Fig. 5 that the neck of plastic deformations has formed immediately in two places, which is practically impossible. It testifies to the fact that the calculation model of structural-gradient samples is not absolutely correct and needs further improvement.

\section{References}

1. A. Popovich, V. Sufiiarov, Metal Powder Additive Manufacturing, New Trends in 3 D Printing, Chapter 10, InTech, (2016) DOI: 10.5772/63337.

2. I. A. Roberts, et al. Int. J. of Machine Tools and Manufacture. 49 (2009)

3. D. V. Ivanov, A. V. Dol, Introduction to the Ansys Workbench. Study guide (Amirit, Saratov, 2016)

4. Post-Processing of Models Ansys Mechanical APDL by Means of Ansys Workbench. [online], Available at: http://www.ansys.soften.com.ua/blog/158-postprotsessing-modelej-ansys-mechanical-apdl-pri-pomoshchi-ansys-workbench.html (2018)
5. A. V. Gusarov, et al. Applied Surface Science 254 (2007)

6. V. A. Popovich, et al. Materials \& Design. 114 (2017) 